\title{
Correction to: Modeling the Effect of HIV/AIDS Stigma on HIV Infection Dynamics in Kenya
}

\author{
Ben Levy ${ }^{1} \cdot$ Hannah E. Correia ${ }^{2,3}$. Faraimunashe Chirove ${ }^{5}$. \\ Marilyn Ronoh ${ }^{4} \cdot$ Ash Abebe $^{5}$. Moatlhodi Kgosimore ${ }^{6}$. Obias Chimbola ${ }^{7}$. \\ M. Hellen Machingauta ${ }^{7}$ Suzanne Lenhart ${ }^{8} \cdot$ K. A. Jane White ${ }^{9}$
}

Published online: 12 May 2021

(c) The Author(s) 2021

\section{Correction to: Bulletin of Mathematical Biology (2021) 83:55 https://doi.org/10.1007/s11538-021-00891-7}

The original version of the article unfortunately contains mistakes.

The spelling of the third author name and affiliation information were incorrect.

The correct information is given below.

Faraimunashe Chirove, Department of Mathematics and Applied Mathematics, University of Johannesburg, South Africa.

The original article has been corrected.

Publisher's note Springer Nature remains neutral with regard to jurisdictional claims in published maps and institutional affiliations.

The original article can be found online at https://doi.org/10.1007/s11538-021-00891-7.

K. A. Jane White

maskajw@bath.ac.uk

1 Department of Mathematics, Fitchburg State University, Fitchburg, MA, USA

2 Harvard Data Science Initiative, Harvard University, Cambridge, MA, USA

3 Department of Biostatistics, Harvard University, Boston, MA, USA

4 School of Mathematics, University of Nairobi, Nairobi, Kenya

5 Department of Mathematics and Applied Mathematics, University of Johannesburg, Johannesburg, South Africa

6 Department of Biometry and Mathematics, Botswana University of Agriculture and Natural Resources, Gaborone, Botswana

7 Mathematics and Statistical Sciences, Botswana International University of Science and Technology, Palapye, Botswana

8 Mathematics Department, University of Tennessee, Knoxville, TN, USA

9 Department of Mathematical Sciences, University of Bath, Bath, UK 